Ann. Biol. anim. Bioch. Biophys., 1979, 19 (3 B), 729-732.

\title{
Influence de la cinétique d'évacuation gastrique de l'aliment sur l'absorption chez le veau préruminant
}

\author{
par R. TOULLEC, P. GUILLOTEAU, J. Y. COROLLER \\ avec la collaboration technique de Marguerite BEAUFILS, S. BOUSSION, Michèle FORMAL et \\ Y. MANIS \\ Station de Recherches zootechniques, I.N.R.A., \\ 65, rue de Saint-Brieuc, 35042 Rennes Cedex.
}

Summary. Effect of gastric emptying kinetics on absorption in the preruminant calf.

The abomasal emptying rate of fat, proteins, and sometimes lactose, increases when skim milk in milk substitutes is replaced by other protein sources. The aim of this study was to determine the effect of this acceleration on absorption and to indirectly verify previous results on abomasal emptying in calves fitted with a duodenal reentrant cannula. Two diets were used, a control and a fish diet. The control diet contained skim milk powder as the only protein source, while 74 p. 100 of the proteins of the fish diet were provided by partly hydrolyzed fish protein concentrate. Eight bull calves were studied ; 4 were first fed the control diet and 4 the fish diet. The diets were then switched after 1 or 2 days of blood sampling from the external jugular vein. The concentrations of plasma triglycerides and blood free $\alpha$-amino nitrogen were lower before the morning meal with the fish diet than with the control diet; these same concentrations were then higher $1.5 \mathrm{hrs}$ later with the fish diet than with the control diet and remained so until 4.5 and 6.5 hrs, respectively (fig. 1). There was no significant difference in the levels of plasma non-esterified fatty acids. The concentrations of plasma glucose were the same with the two diets before and $0.5 \mathrm{hr}$ after the meal, but then decreased quicker with the fish diet. In conclusion, the rate of fat and amino acid absorption increased when milk proteins in the milk substitute were replaced by hydrolyzed fish proteins. This confirmed previous studies on the kinetics of abomasal emptying in calves fitted with a duodenal reentrant cannula and eating diets similar to those in the present study. The quicker decrease of glycemia with the fish diet was probably not due only to faster lactose digestion, but also to more intensive glucose utilization; the change in the insulin level might explain this.

Le remplacement de la poudre de laif écrémé par d'autres sources de protéines, dans les aliments d'allaitement distribués au veau préruminant, entraîne une accélération de l'évacuation gastrique des lipides, des protéines el parfois du lactose (Guilloteau et al., 1975). Le buł de cet essai éłait d'éfudier les conséquences de cette accélération sur l'absorption et de vérifier indirectement les cinétiques d'évacuation gastrique obtenues sur des veaux porteurs d'une canule réentrante du duodénum.

Deux aliments d'allaitement (Témoin ef Poisson) contenant respectivement 23.5 et 24,8 p. 100 de protéines et 18,2 et 17,6 p. 100 de matières grasses par rapport à la 
matière sèche, ont été préparés. Dans l'aliment Témoin, les protéines étaient apportées presque exclusivement par de la poudre de lait écrémé ; dans l'aliment Poisson, elles provenaient en majeure partie (74 p. 100) d'un concentrat de poisson partiellement hydrolysé, le reste étant fourni par de la poudre de lactosérum et des acides aminés de synthèse. L'évacuation gastrique de deux aliments très voisins de ceux utilisés dans cet essai a été étudiée précédemment (Guilloteau ef al., 1975).

Huit veaux mâles, Frisons ou croisés Normand $\times$ Frison, ont été utilisés ; 4 d'entre eux ont d'abord reçu l'aliment Témoin et les 4 autres l'aliment Poisson. Les régimes ont été intervertis après 1 (6 veaux) ou 2 ( 2 veaux) journées de prises de sang. Les aliments ont été distribués au seau, en 2 repas par jour, apportant au total $53 \mathrm{~g}$ de matière sèche par $\mathrm{kg}$ de poids vifo,75. Les veaux étaient âgés de $77 \mathrm{j} \pm 9$ et pesaient $97 \mathrm{~kg} \pm 8$, au moment des prélèvements (moyenne \pm écart-type de la moyenne) ; leurs gains de poids vif, au cours des semaines où ont été réalisés les prélèvements, ont été respectivement de $1346 \pm 72$ et de $1094 \mathrm{~g} / \mathrm{j} \pm 83$, avec les aliments Témoin et Poisson.

Les prises de sang ont eu lieu au moins 8 jours après la fin des transitions. Elles ont été effectuées avant et 0,$5 ; 1 ; 1,5 ; 2 ; 3 ; 4,5$ et 6,5 h après le repas du matin, à l'aide d'un cathéter placé la veille dans la veine jugulaire externe. La triglycéridémie plasmatique a été mesurée à l'aide d'une méthode adaptée de celles de Giegel, Ham et Clema (1975) et de Mendez, Franklin et Gahagan (1975), la teneur en azote $\alpha$ aminé libre selon la technique de Michel (1968), la glycémie plasmatique par la méthode à la glucose-oxydase et la teneur en acides gras non estérifiés du plasma par la méthode de Dole ef Meinertz (1960).
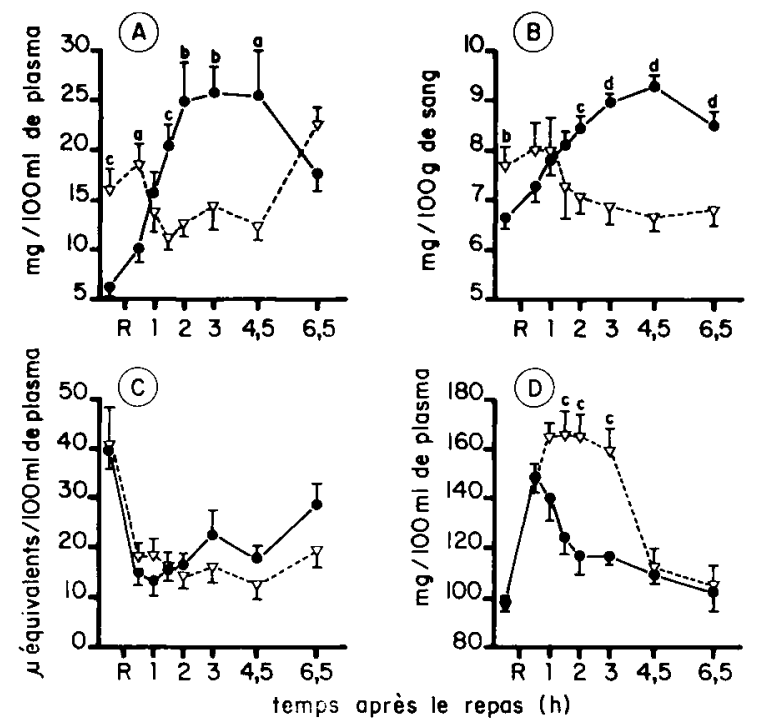

FIG. 1." - Evoluticn des teneurs plasmatiques en triglycérides (A), acides gras non estérifiés (C) et glucose (D) ef de la teneur sanguine en azơe $\alpha$ aminé libre (B) (moyennes et écarts-types des moyennes). $\nabla---\Delta$ Alimenf Témoin (7 veaux, 9 cinétiques); $\longrightarrow$ Aliment Poisson (8 veaux, 10 cinétiques). $a, b, c$ et $d$ : différences entre régimes significatives à $P<0,05,0,02,0,01$ et 0,001 . 
Lorsque les veaux reçoivent l'aliment Témoin, la triglycéridémie plasmatique diminue jusqu'à $1,5 \mathrm{~h}$ après le repas (fig. $1 \mathrm{~A}$ ) ; elle évolue peu jusqu'à $4,5 \mathrm{~h}$ puis elle augmente fortement, atteignant à 6,5 h 1,8 fois la valeur observée à 4,5 h. Cette évolution est voisine de celle décrite par Bazin et Brisson (1976) chez des veaux recevant un lait de remplacement riche en poudre de lait écrémé. Avec l'aliment Poisson, la triglycéridémie obtenue à jeun est 2,6 fois plus faible qu'avec l'aliment Témoin ; elle augmente considérablement jusqu'à $2 \mathrm{~h}$ après le repas où elle est 2 fois plus forte qu'avec l'aliment Témoin, reste plus élevée jusqu'à 4,5 h et ne redevient inférieure qu'à $6,5 \mathrm{~h}$.

La teneur sanguine en azote $\alpha$ aminé libre diminue $1,5 \mathrm{~h}$ après l'ingestion de l'aliment Témoin et demeure ensuite inférieure à la valeur obtenue à jeun (fig. 1 B). Avec l'aliment Poisson, la valeur à jeun est 1,2 fois plus faible qu'avec l'aliment Témoin ; elle augmente ensuite jusqu'à $4,5 \mathrm{~h}$ après le repas où elle est 1,4 fois plus forte qu'avec l'aliment Témoin ef reste plus élevée jusqu'à 6,5 h. Patureau-Mirand, Prugnaud ef Pion (1971) ont de même observé une diminution de la teneur postprandiale en acides aminés libres du sang, lorsque les protéines de l'aliment provenaient du lait ef une augmentation quand elles étaient fournies par du tourteau de soja ou des levures d'alcanes.

Quel que soit le régime, la teneur en acides gras non estérifiés du plasma est élevée lorsque les veaux sont à jeun (fig. 1C). Contrairement aux résultats de Bazin et Brisson (1976), elle diminue pendant la demi-heure qui suit le repas, à l'issue de laquelle elle n'atteint plus en moyenne que 42 p. 100 de la valeur obtenue à jeun. A partir de la troisième heure, elle devient plus élevée avec l'aliment Poisson qu'avec l'aliment Témoin, mais les différences observées ne sont jamais significatives.

La glycémie plasmatique augmente avec les 2 aliments pendant la première demiheure qui suit le repas. Avec l'aliment Témoin, elle s'accroît jusqu'à 1 h et ne diminue fortement qu'après $3 \mathrm{~h}$ (fig. 1D). En revanche, avec l'aliment Poisson, elle commence à diminuer entre 0,5 et $1 \mathrm{~h}$; à $2 \mathrm{~h}$, sa valeur n'atteint plus que $71 \mathrm{p} .100$ de celle observée avec l'aliment Témoin. A 4,5 et $6,5 \mathrm{~h}$, les valeurs sont très voisines pour les 2 régimes.

En conclusion, le remplacement des protéines du lait par celles du poisson dans l'aliment d'allaitement, entraîne une accélération de l'absorption des lipides et des acides aminés. L'évolution des teneurs sanguines en triglycérides et en azote $\alpha$ aminé libre est en accord avec les cinétiques d'évacuation gastrique obtenues précédemment (Guilloteau ef al., 1975) sur des veaux porteurs d'une canule réentrante du duodénum, avec des aliments très voisins de ceux utilisés dans cet essai ; il semble donc que ces cinétiques n'étaient pas très différentes de la réalité. La diminution plus rapide de la glycémie avec l'aliment Poisson n'est peut-être pas due exclusivement à l'accélération de la digestion du lactose mais également à une utilisation plus intense du glucose ; la mesure de l'insulinémie permettra vraisemblablement de mieux l'interpréter.

Commission CNERNA Digestion-Absorption/Association des Physiologisfes, Paris 5-6 octobre 1978.

\section{Références}

BAZIN R. C., BRISSON G. J., 1976. Plasma lipids, ketone bodies and glucose concentrations in calves fed high and low fat milk replacers. J. Dairy Sci., 59, 1301-1305.

DOLE V. P., MEINERTZ H., 1960. Determination of long chain fatty acids in plasma and tissues. J. biol. Chem., 235, 2595-2599. 
GIEGEL J. L., HAM A. B., CLEMA W., 1975. Manual and semi-automated procedure for measurement of triglycerides in serum. Clin. Chem., 21, 1575-1581.

GUILLOTEAU P., PARUELLE J. L., TOULLEC R., MATHIEU C.-M., 1975. Utilisation des protéines par le veau préruminant à l'engrais. III. Influence du remplacement des protéines du lait par celles du poisson sur la vidange stomacale. Ann. Zootech., 24, 243-253.

MENDEZ J., FRANKLIN B., GAHAGAN H., 1975. Simple manual procedure for determination of serum triglycerides. Clin. Chem., 21, 768-769.

MICHEL M. C., 1968. Dosage des acides aminés et amines par la ninhydrine. Amélioration pratique. Ann. Biol, anim. Bioch. Biophys., 8, 557-563.

PATUREAU-MIRAND P., PRUGNAUD J., PION R., 1971. Influence de la nature des protéines des aliments d'allaitement sur l'amino-acidémie libre du veau préruminant. $X^{\mathrm{e}}$ Congr. int. Zootech. Thème VII, Versailles. 